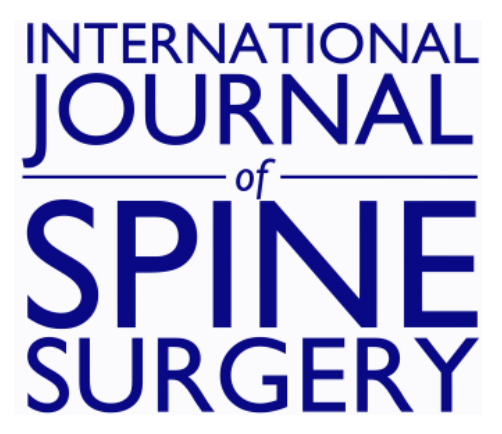

\title{
Percutaneous interspinous distraction device for the treatment of lumbar spinal canal stenosis: Clinical and radiographic results at 2-year follow-up
}

Wicharn Yingsakmongkol, Chaiyos Chaichankul and Worawat Limthongkul

Int J Spine Surg 2014, 8 ()

doi: https://doi.org/10.14444/1032

http://ijssurgery.com/content/8/32

This information is current as of April 26, 2023.

Email Alerts Receive free email-alerts when new articles cite this article. Sign up at: http://ijssurgery.com/alerts 


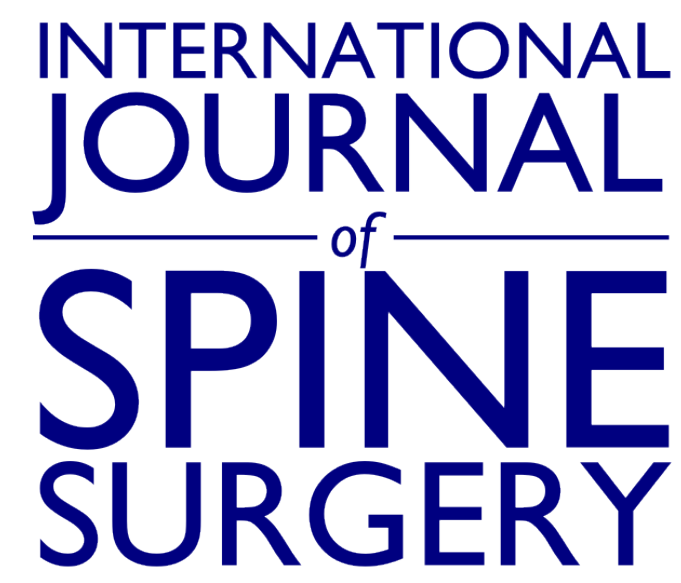

This article generously published free of charge by the International Society for the Advancement of Spine Surgery.

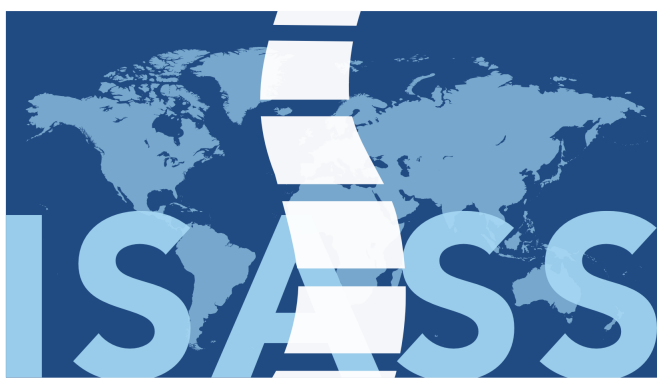

INTERNATIONAL SOCIETY for the ADVANCEMENT of SPINE SURGERY 


\section{Percutaneous interspinous distraction device for the treatment of lumbar spinal canal stenosis: Clinical and radiographic results at 2-year follow-up}

Wicharn Yingsakmongkol, MD, Chaiyos Chaichankul, MD, Worawat Limthongkul, MD

Department of Orthopaedics, Faculty of Medicine, Chulalongkorn University, Bangkok, Thailand

\section{Abstract}

\section{Objective}

To evaluate the effectiveness of the In- space (Synthes, Umkirch, Germany) and the correlation between radiographic parameters and clinical outcome in patients with lumbar spinal canal stenosis (LSS).

\section{Methods}

Between June 2009 and May 2013, 56 patients with LSS underwent In-space by one senior surgeon. All of the patients were evaluated both clinically and radiographic measurements before the procedure and each visit at the postoperative follow-up. Preoperative and postoperative X-ray imaging was performed before the procedure and at follow-up to assess the correlation with the clinical outcome. Radiological measurements and clinical outcomes were recorded to establish a relationship between the radiographic parameters and clinical outcome of this procedure. All patients had at least 2 years of follow-up.

\section{Results}

The mean VAS score of back pain decreased significantly $(\mathrm{p}<0.05)$.

\section{Conclusions}

Our data suggest that percutaneous interspinous devices are a good alternative to treat LSS. The device offers significant decrease in back pain, leg pain and ODI score with 2-year lasting relief from symptoms. The increased intervertebral foramenal space explains the improvement of leg pain, but the mechanism of back pain relief remains unclear. A very weak correlation between the radiographic changes and improvement of pain was found. 


\section{Introduction}

Lumbar spinal canal stenosis (LSS) is one of the most common degenerative spinal disorders. Treatment of symptomatic LSS includes conservative and surgical management. The treatment options may vary from activity modification, nonsteroidal anti-inflammatory drugs, physiotherapy, and epidural injection for those with mild symptoms or unfit for surgery to surgical decompression with or without fusion in patients who fail to respond to conservative measures. Several studies ${ }^{1-5}$ reported that surgical treatment showed significantly more improvement in outcome than nonsurgical treatment. Recently, minimally invasive spine surgery has been increasing role in treatment of several spinal conditions. Various interspinous spacers such as Diam (Medtronic, Memphis, Tennessee, USA), Wallis (Abbott Spine, Austin, Texas, USA) and $\mathrm{X}$ Stop (Medtronic, Memphis, Tennessee, USA) have been introduced for an alternative treatment. ${ }^{6-14}$ There are some studies reported the outcomes of these treatments. The Inspace (Synthes, Umkirch, Germany) (Figure 1) is a new percutaneous device considered for the treatment of LSS. The In-space device is a PEEK (polyether-ether ketone) material radiolucent body, which is undisturbed visualization by screw and wings made of titanium alloy to allow proper radiographic assessment of, implant position. It is available in 5 different sizes from 8 to $16 \mathrm{~mm}$ (in $2 \mathrm{~mm}$ increments). According to limited of clinical trials and clinical outcome data, the efficacy of this procedure still remains controversy. However, best to our knowledge, no study has yet been reported the correlation between radiographic measurements after implantation of the In-space device and clinical outcome.

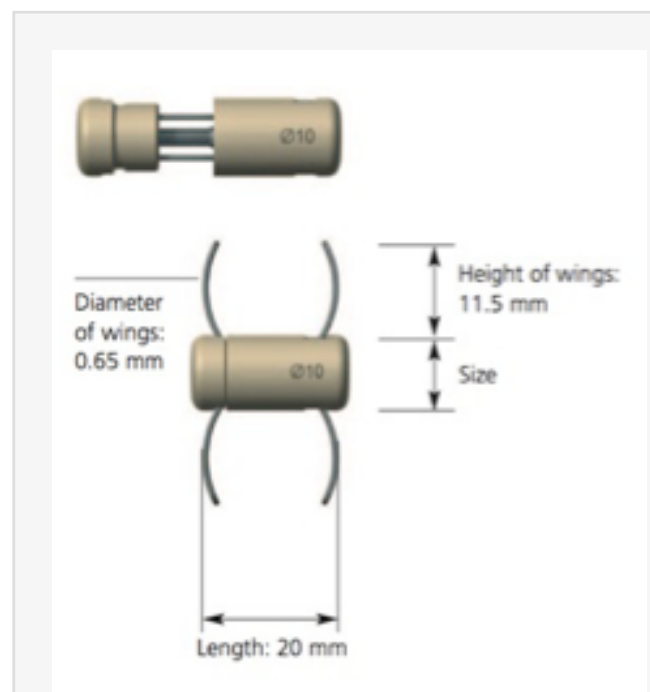

Fig. 1. The In-space device (Synthes, Umkirch, Germany).

The purpose of this study is to report the radiographic measurements and 2-year clinical outcome from a prospective study of symptomatic LSS patients with the In-space. 


\section{Materials and methods}

Between June 2009 and May 2013, 56 consecutive patients with LSS were treated by Inspace in our institution. This procedure was performed by our senior author. The inclusion criteria of the In-space were the presence of symptomatic level between L1 to Sacrum, which failed conservative treatment in 3 months. LSS symptoms included central, lateral and foraminal stenosis with leg, buttock or groin pain, facet joints pain, soft disc herniation with discogenic back pain or sciatica and degenerative spondylolisthesis grade I. Exclusion criteria included spine fractures, sequestrated disc herniation, infection, previous surgery at the index level, degenerative spondylolisthesis $>$ grade I, severe osteoporosis, cauda equina syndrome, severe spinal stenosis and obesity $(\mathrm{BMI}>40)$. Patients with inadequate radiographs or incomplete 2 years follow up were also excluded.

All patients had preoperative x-ray, MRI and completed self-assessment questionnaire. Quantitative image evaluation included standing lateral, posteroanterior, flexion and extension radiographs were also performed. All measurements were recorded using the DICOM imaging software. The radiographic images were precalibrated to provide a $0 \%$ of magnification.

Radiographic measurements before and after procedure as described by Sobottke et al. ${ }^{15}$ were included as follows:

- Foraminal height (FH) (mm)

Maximum distance between the inferior margin of the pedicle of the superior vertebra and the superior margin of the pedicle of the inferior vertebra.

- Foraminal width (FW) (mm)

The anterior-posterior width of the foramen measured in the horizontal plane as extension of the tangent of the inferior endplate.

- Foraminal cross-sectional area (FA) $\left(\mathrm{mm}^{2}\right)$

The margins of the foramen were marked with the cursor, and the program DicomWorks measured the cross-sectional area of the foramen.

- Anterior disc height $(\mathrm{aDH})$ and posterior disc height $(\mathrm{pDH})(\mathrm{mm})$

The anterior and posterior disc heights were measured in the planes of the anterior and posterior surfaces of the adjacent vertebral bodies. Therefore, the distance between the intersections of the vertical line of the tangent of the superior endplate and the tangent of the inferior endplate was measured. The vertical line started at the superior-anterior, respectively superior-posterior edge of the lower vertebra.

- Intervertebral angle (IA) $\left(^{\circ}\right)$

The angle between the tangent of the superior endplate and that of the inferior endplate of the vertebral segment was measured. 
With the patient in prone position, once the segment to be treated was identified under fluoroscopic guidance. An approximately $1.5-\mathrm{cm}$ incision at right or left side was performed over the pathologic segment. All patients were administered antibiotic prophylaxis ( $1 \mathrm{~g}$ of Cephazolin) once per day starting from the day of the procedure. In addition, the operating time during operation and complications were recorded. The Visual Analogue Scale (VAS) and Oswestry Disability Index (ODI) were used for evaluate pain and functional assessment. Patients underwent serial follow-up evaluations. Two-year follow-up data was obtained in all patients. At each follow-up visit, patients were evaluated both clinically and radiographically. Radiographs (Figure 2) were obtained at immediate postoperative and 1 week, 1 month, 3 months, 6 months, 9 months, 12 months, 18 months and 24 months afterwards. Only patients who have completed a minimum follow-up period of 2 years were included in this study.

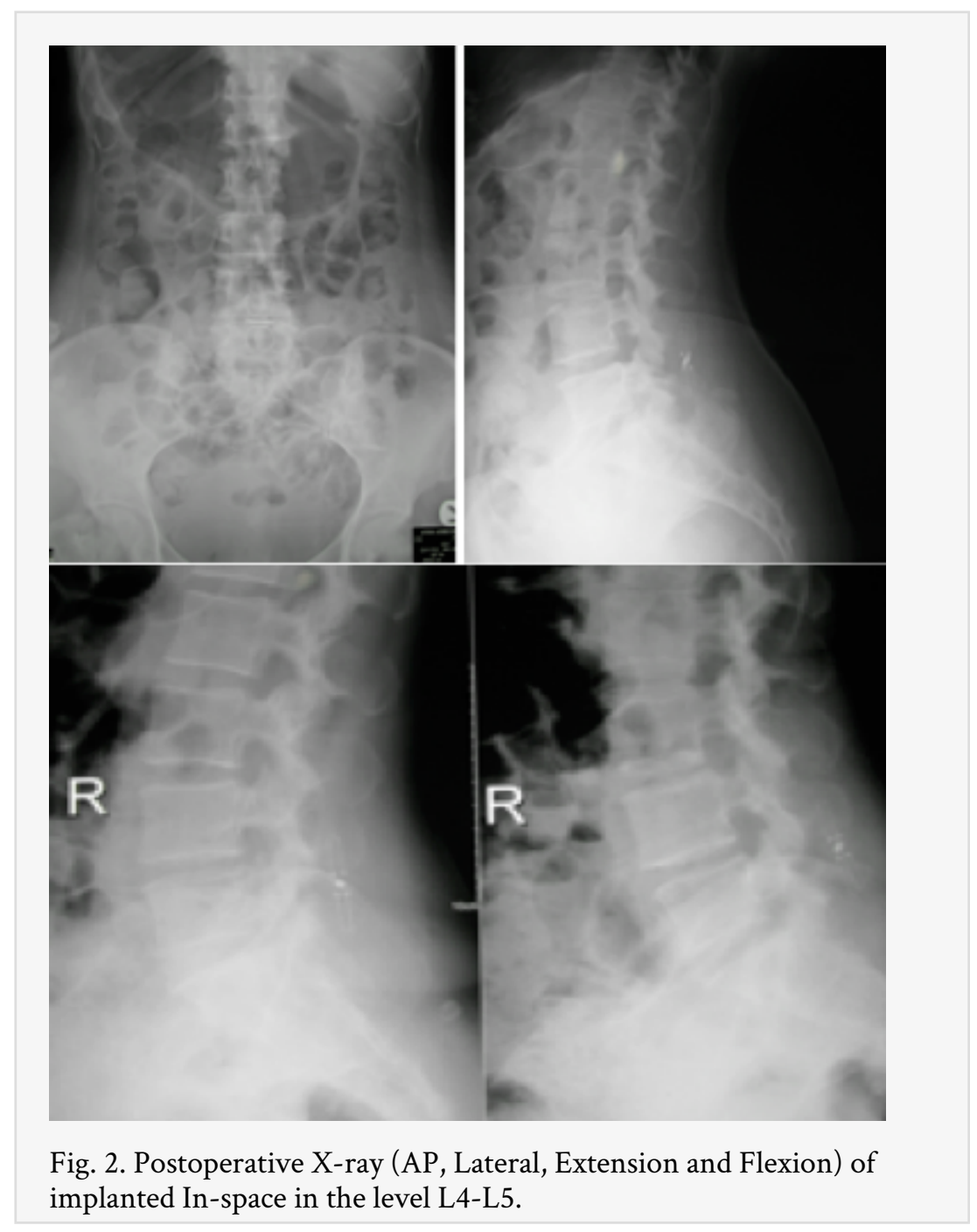

\section{Statistical Analyses}

The GraphPad Prism 5.01.336 software (La Jolla, CA, USA) was used for statistical analysis. Descriptive statistic was used for subjects' demographics and dimensional demographic diseases. Comparative statistical analyses between genders and disease characteristics were made using the t-test for parametric continuous data and the Mann-Whitney $U$ test for nonparametric continuous data. A $p$ value of $<0.05$ indicated a 
significant difference. The data concerning the questionnaires collected before and after the procedures have been statistically evaluated using the nonparametric Wilcoxon signed-rank test (Prism 5 for Windows, GraphPad Software Inc., San Diego, CA). A p value $<0.05$ was considered statically significant for the evaluation of pain and life quality of the patients. Informed consents were obtained from all patients who participated in this procedure. The ethics committees at our center approved the study and the institutional review board approved the study proposal.

\section{Results}

The In-space devices were implanted in fifty-six patients. Twenty-four patients were males and 32 were females. Mean age of the patients was 44 years (range 27-64). The demographic data are shown in Table 1. There were no statistical differences between genders in terms of age. The spacer was placed at L3-L4 in five cases, L4-L5 in fortyseven cases and L5-S1 in four cases.

Table 1. Patient Characteristics $(\mathrm{n}=56)$.

\begin{tabular}{|l|l|}
\hline Male-female ratio & $24: 32$ \\
\hline Patient age (range) & 44 years (27-64) \\
\hline $\begin{array}{l}\text { Diagonosis } \\
\text { Number patients with stenosis } \\
\text { Number patients with spondylolisthesis }\end{array}$ & 8 \\
\hline $\begin{array}{l}\text { Lumbar level } \\
\text { L3-L4 }\end{array}$ & 5 \\
\hline $\begin{array}{l}\text { L4-L5 } \\
\text { L5-S1 }\end{array}$ & 47 \\
\hline Number of levels treated & 4 \\
\hline $\begin{array}{l}\text { One level } \\
\text { Two levels }\end{array}$ & 52 \\
\hline Mean operative time (range) per level & 8 minutes (5-20) \\
\hline Number patients with complications & None \\
\hline Number patients with failed of treatment & 3 \\
\hline Follow-up & 2 years \\
\hline
\end{tabular}

The mean VAS score of back pain decreased significantly $(\mathrm{p}<0.0001)$ from 6.56 preoperative to 2.64 at 1 week after the procedure however, no statistically significant difference in back pain was found after 1 week to 2-year follow-up. (Figure 3) The mean VAS score of leg pain decreased significantly $(\mathrm{p}<0.0001)$ from 7.47 preoperative to 2.28 at 1 week after the procedure. The leg pain score remain unchanged until 2-year followup. The ODI score was found decreased after the procedure in most patients. (Figure 4) A reduction of clinical symptoms was observed. 

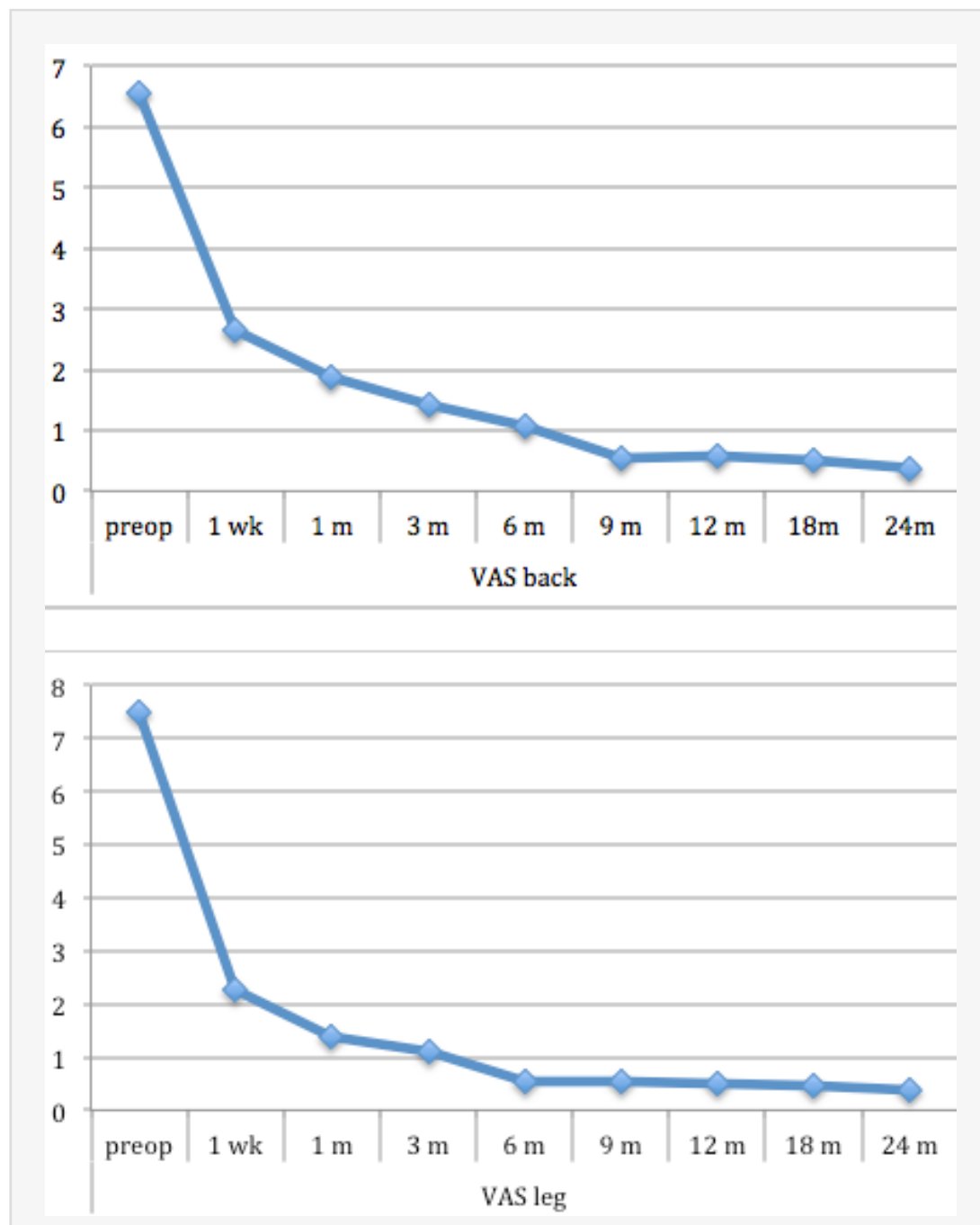

Fig. 3. Mean VAS score of back pain and the mean VAS score of leg pain before and after the procedure.

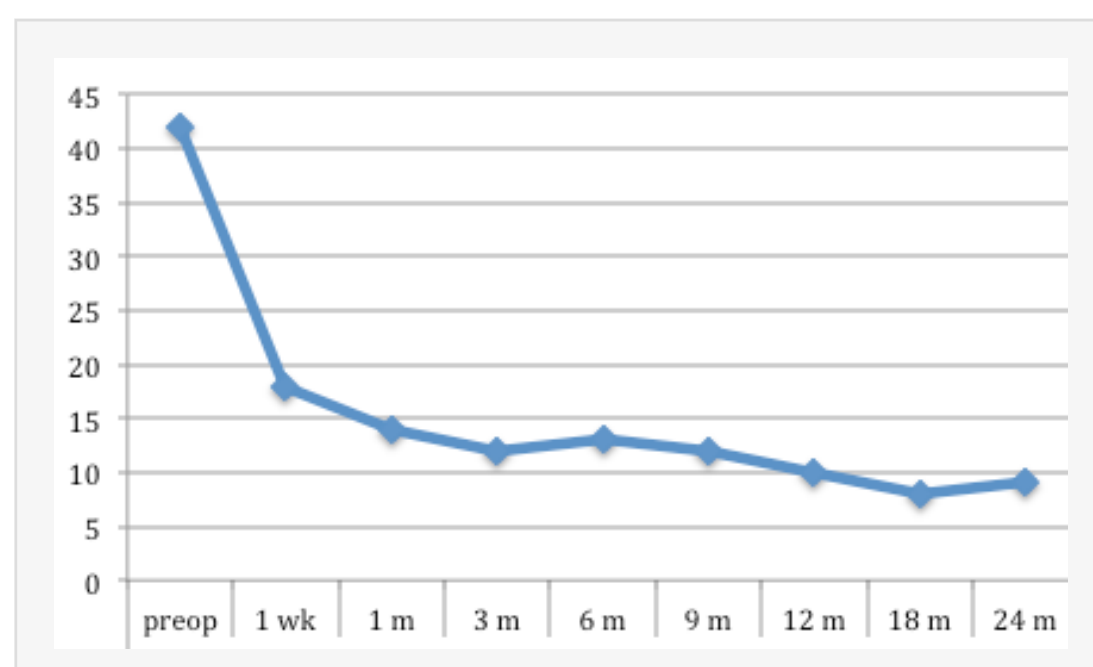

Fig. 4. Mean ODI score reduction. 
Radiological measurements documented an increased size of the foraminal height and foraminal width significantly $(\mathrm{p}<0.0001)$ in most cases (Figure 5). Similarly, significant improvement of foraminal area was found after the procedure $(p<0.0001)$ (Figure 6). Although, variations of the intervertebral disc height were not significant, increase posterior disc height leading to decrease in intervertebral angle was found after the procedure $(\mathrm{p}<0.001)$ (Figure 5 and Figure 7$)$. 


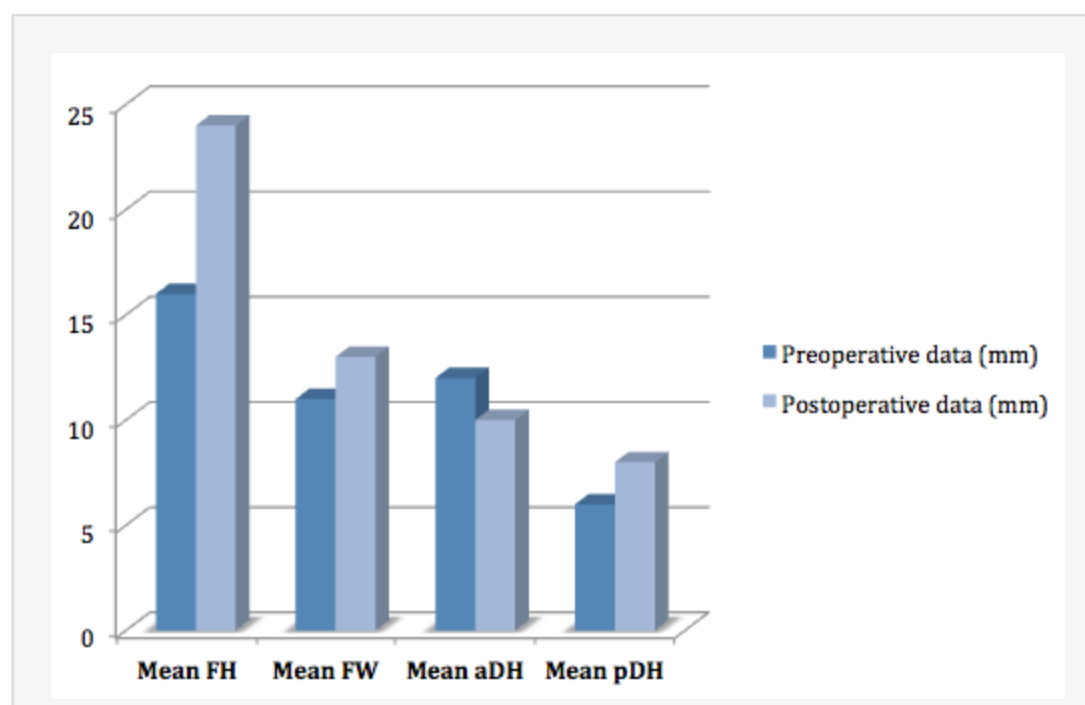

Fig. 5. Preoperative and postoperative mean FH, FW, aDH and pDH.

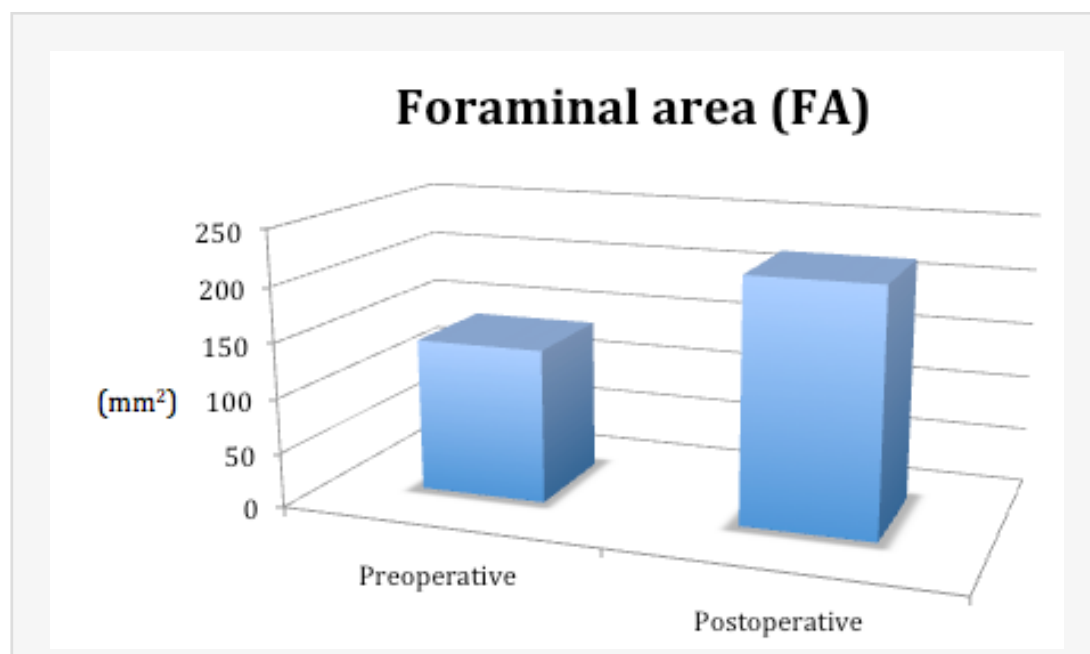

Fig. 6. Preoperative and postoperative mean FA.

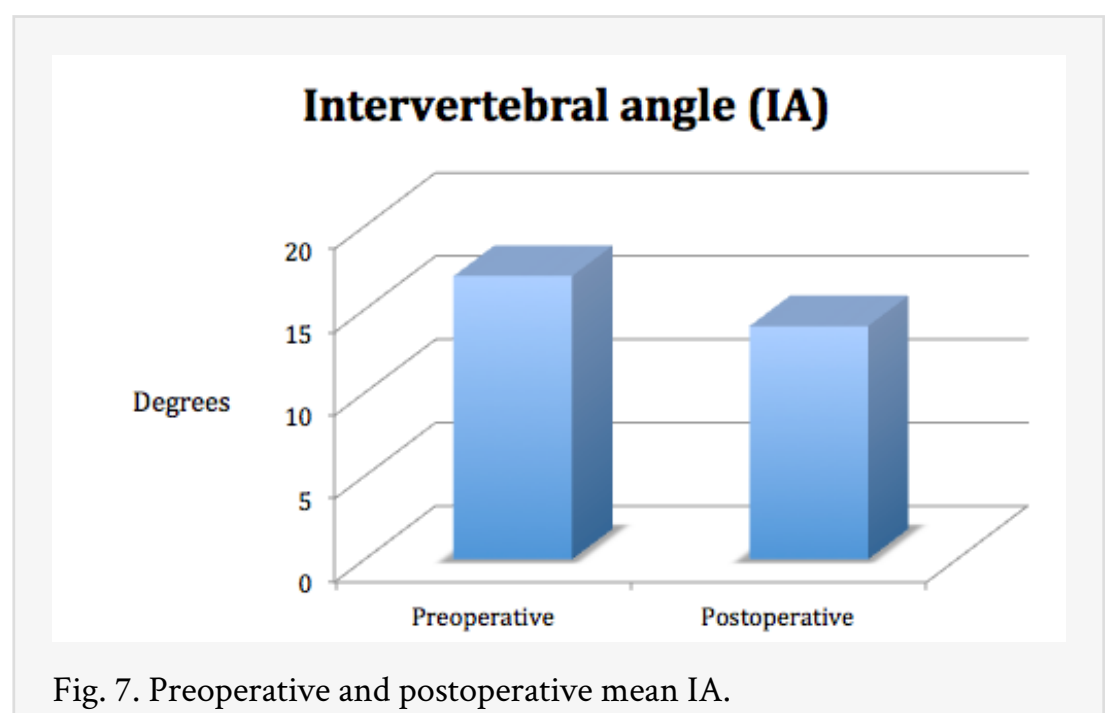


The variation of the intervertebral space height measured on the posterior wall was not significant. It was a very weak correlation between the radiographic changes and the magnitude of pain improvement $(\mathrm{r}=0.07, \mathrm{p}<0.05)$.

The average operative time was 8 minutes per level (range 5- 20 minutes) and the blood loss was minimal which did not exceed $5 \mathrm{ml}$. There were no intraoperative complications or postoperative complications. Average stay in hospital was 1 day. Outcome data were obtained at a minimum follow-up period of 2 years. Most patients had improvement in the VAS and ODI score except three patients who were not satisfied with the outcome of this treatment and needed to convert by open procedure.

\section{Discussion}

Until now many dynamic stabilization devices have been undertaken in the area of lumbar spinal diseases. ${ }^{6-15}$ Previous biomechanical cadaveric studies ${ }^{16-18}$ have shown the device to increase the dimensions of the canal and neural foramens, reduce extension, and allow flexion and unrestricted axial rotation and lateral bending at the level of implantation. In vitro studies ${ }^{17,19,20}$ have demonstrated reduced the mean peak pressure, average pressure, contact area, and force at the implanted level. MRI studies have demonstrated increased canal and neural foraminal area after implantation of these devices. More recently, new muscle-sparing technology has come into use with tubular access. This has now been adapted to the percutaneous placement of spinal instrumentation with including interspinous spacer. The interspinous spacer is a motion-preserving implant to provide symptomatic relief in selected patients without the need for spinal fusion. Therefore, recent development like the In-space (Synthes, Umkirch, Germany) has been used in the treatment of lumbar spinal stenosis. This technique requires smaller incision, result in less soft-tissue disruption. The In-Space device was developed to treat degenerative lumbar stenosis in patients. Surgical procedure can be performed under local anesthesia with the patient positioned prone and in slightly flexion. The procedure requires that the paraspinal muscles not be stripped from the spinous processes and all midline structures are left intact. The In-Space device is inserted between the spinous processes at the affected level and places the motion segment in slight flexion, while at the same time preventing extension. This device has been proposed alternative to rigid instrumented fusion, with the advantages of a more limited and less morbid surgical procedure that may confer less risk of adjacent segment degeneration. The limited soft-tissue disruption achieved by this procedure may reduce the development of adjacent segment disease. Park et al. ${ }^{21}$ investigated the kinematic characteristics of the lumbar spine implanted with this device. The results indicate that it significantly reduced the ROM at the implanted level during flexion-extension and did not statistically significantly affect the ROM at the adjacent levels. In addition, the spacer did not change the kinematic characteristics during axial rotation and lateral bending at any level. The device both stabilizes the spine and reduces the intervertebral disc pressure at the instrumented level during extension. Swanson et al. ${ }^{22}$ presented the data on a series of 33 patients who showed that interspinous spacer placement significantly reduced the disc pressure at the implanted level, but did not significantly affect disc pressures at the adjacent levels. 
According to our study, local kyphosis was occurred at the implanted level but there are no long-term clinical data regarding the effects of increased kyphosis as a result of interspinous process spacer placement. In short-term clinical data there was no significant effect from this result. The rational of percutaneous interspinous process spacer devices appears to be sound and is well supported by biomechanical studies. The concept that an implant placed between the spinous processes might provide relief for patients suffering from neurogenic intermittent claudication came about from a straightforward clinical observation; most of these patients get relief of symptoms when they bend forward and flex their spines and conversely their symptoms worsen when they stand erect and extend their spines.

Our clinical study suggested promising short-term result when this device is properly applied in appropriately selected patient. We found that most patients experiencing measurable improvement in symptoms and function outcomes in our study as the previous other interspinous devices studies. ${ }^{7,8,10,11,13-16}$ Short-term clinical outcomes following percutaneous implantation with interspinous spacer system demonstrate amelioration of low back and leg pain and improvements in function in patients with LSS who are unresponsive to conservative treatments. No intraoperative or postoperative complication was occurred in our study such as spinous process fracture. According to other studies with interspinous devices, a number of spinous process fractures can be occurred up to $20 \% .{ }^{23-26}$ Despite the limitations, we have shown that implantation of the In-space device is relatively safe and effective, short-term treatment for patients with LSS and other significant comorbidities. Therefore, in order to get more information concerning the optimal indication, we concern about the clinical efficacy and durability of benefit from this device. So a definition of the role of this device will come from long-term follow-up studies and clinical studies that compare this device with conservative treatment and traditional decompression surgery. The authors are planning to present such facts in the future studies.

\section{Conclusions}

According to our results suggest that use of a percutaneous interspinous device is a good alternative to treat LSS. The device offers significant decrease in back pain, leg pain and ODI score with 2-year lasting relief from symptoms. The increased intervertebral foramenal space explains the improvement of leg pain, but the mechanism of back pain relief remains unclear. A very weak correlation between the radiographic changes and improvement of pain was found. Placement of the percutaneous implant is straightforward and typically requires minimal operative time, easy access, and low risk. The results of this prospective study indicate that the In-space might provide significant short-term improvement. It is a safe, effective, and less invasive alternative for treatment of lumbar spinal stenosis.

\section{References}

1. Amundsen T, Weber H, Nordal HJ et al (2000) Lumbar spinal stenosis: conservative or surgical management? a prospective 10-year study. Spine 25(11): 1424-1435. 
2. Atlas SJ, Keller RB, Robson D, et al (2000) Surgical and nonsurgical management of lumbar spinal stenosis: four-years outcomes from the Maine lumbar spine study. Spine 25: 556-562.

3. Costa F, Sassi M, Cardia A, et al (2007) Degenerative lumbar spinal stenosis: analysis of results in a series of 374 patients treated with unilateral laminotomy for bilateral microdecompression. J Neurosurg 7:579-586.

4. Malmivaara A, Slatis P, Heliovaara M, et al (2007) Surgical or non-operative treatment for lumbar spinal stenosis? A randomized controlled trial. Spine 32:1-8.

5. Weinstein JN, Tosteson TD, Lurie JD, et al (2008) Surgical versus non-surgical therapy for lumbar spinal stenosis. N Engl J Med 358:794-810.

6. Fuchs PD, Lindsey DP, Hsu KY, et al (2005) The use of an interspinous implant in conjunction with a graded facetectomy procedure. Spine 30:1266-1272.

7. Anderson PA, Tribus CB, Kitchel SH (2006) Treatment of neurogenic claudication by interspinous decompression: application of the $\mathrm{X}$ Stop device in patients with lumbar degenerative spondylolisthesis. J Neurosurg 4:463-471.

8. Hsu KY, Zucherman JF, Hartjen CA, et al (2006)Quality of life of lumbar stenosistreated patients in whom the X Stop interspinous device was implanted. J Neurosurg 5:500-507.

9. Bono CM, Vaccaro AR (2007) Interspinous process devices in the lumbar spine. J Spinal Disord Tech 20:255-261.

10. Kim KA, McDonald M, Pik JH, et al (2007) Dynamic intraspinous spacer technology for posterior stabilization: case-control study on the safety, sagittal angulation, and pain outcome at 1-year follow-up evaluation. Neurosurg Focus 22:E7

11. Richards JC, Majumdar S, Lindsey DP, et al (2005) The treatment mechanism of an interspinous process implant for lumbar neurogenic intermittent claudication. Spine 30:744-749.

12. Schulte TL, Hurschler C, Haversath M, et al (2008) The effect of dynamic, semi-rigid implants on the range of motion of lumbar motion segments after decompression. Eur Spine J 17:1057-1065.

13. Siddiqui M, Smith FW, Wardlaw D (2007) One-year results of X Stop interspinous implant for the treatment of lumbar spinal stenosis. Spine 32:1345-1348.

14. Zucherman JF, Hsu KY, Hartjen CA, et al (2005) A multicenter, prospective, randomized trial evaluating the $\mathrm{X}$ Stop interspinous process decompression system for the treatment of neurogenic intermittent claudication: two-year follow-up results. Spine 30:1351-1358.

15. Sobottke R, Schluter-Brust K, Kaulhausen T, et al (2009) Interspinous implants (X Stop, Wallis, Diam) for the treatment of LSS: is there a correlation between radiological parameters and clinical outcome? Eur Spine J 18(10):1494-1503.

16. Richards JC, Majumdar S, Lindsey DP (2002) Quantitative changes in the lumbar spinal canal with an Interspinous implant. Tran International Meeting on Advanced Spine Techniques, Montreaux.

17. Lindsey DP, Swanson KE, Fuchs P, et al (2003) The effects of an interspinous implant on the kinematics of the instrumented and adjacent levels in the lumbar spine. Spine 28:2192-2197.

18. Siddiqui M, Karadimas E, Nicol M (2006) Influence of X Stop on Neural Foramina and Spinal Canal Area in Spinal Stenosis. Spine 3:2958 -2962. 
19. Minns RJ, Walsh WK (1997) Preliminary design and experimental studies of a novel soft implant for correcting sagittal plane instability in the lumbar spine see comments. Spine 22:1819-1825; discussion 1826-1827.

20. Wiseman CM, Lindsey DP, Fredrick AD, et al (2005) The effect of an inter- spinous process implant on facet loading during extension. Spine 30: 903-907.

21. Park SW, Lim TJ, Park J (2010) A biomechanical study of the instrumented and adjacent lumbar levels after In-Space interspinous spacer insertion. J Neurosurg Spine 12: 560-569.

22. Swanson KE, Lindsey DP, Hsu KY, et al (2003) The effects of an interspinous implant on intervertebral disc pressures. Spine 28:26-32.

23. Bowers C, Amini A, Dailey AT, et al (2010) Dynamic interspinous process stabilization: review of complications associated with the X-Stop device.Neurosurg Focus;28(6):E8.

24. Kim DH, Tantorski M, Shaw J, et al (2011) Occult spinous process fractures associated with interspinous process spacers. Spine15;36(16):E1080-5.

25. Kim DH, Shanti N, Tantorski ME, et al (2012) Association between degenerative spondylolisthesis and spinous process fracture after interspinous process spacer surgery. Spine J:12(6):466-72.

26. Zucherman JF, Telles CJ (2012) Commentary: Interspinous devices, spondylolisthesis, and spinous process-related complications. Spine J;12(6):473-5.

\section{Corresponding Author}

Wicharn Yingsakmongkol, Department of Orthopaedics, Faculty of Medicine, Chulalongkorn University, 1873 Rama IV Road, Bangkok 10330, Thailand.

wyingsak@hotmail.com

\section{Disclosures}

The authors have no benefits or funds received in support of the study and no personal relationships with organizations related to this work.

Published 29 October 2014.

Copyright (C) 2014 ISASS - International Society for the Advancement of Spine Surgery. To see more or order reprints or permissions, see http://ijssurgery.com. 